\title{
Temporal analysis of normalized difference vegetation index (NDVI) and land surface temperature (LST) parameters to detect changes in the Iberian land cover between 1981 and 2001
}

\author{
YVES JULIEN*, JOSE A. SOBRINO, CRISTIAN MATTAR, \\ ANA B. RUESCAS, JUAN C. JIMÉNEZ-MUÑOZ, GUILLEM SÒRIA, \\ VICTORIA HIDALGO, MARIAM ATITAR, BELEN FRANCH and \\ JUAN CUENCA
}

Global Change Unit, Image Processing Laboratory, University of Valencia, P.O. Box 22085, E-46071 Valencia, Spain

(Received 2 September 2008; in final form 29 October 2009)

\begin{abstract}
In past decades, the Iberian Peninsula has been shown to have suffered vegetation changes such as desertification and reforestation. Normalized difference vegetation index (NDVI) and land surface temperature (LST) parameters, estimated from data acquired by the Advanced Very High Resolution Radiometer (AVHRR) sensor onboard the National Oceanic and Atmospheric Administration (NOAA) satellite series, are particularly adapted to assess these changes. This work presents an application of the yearly land-cover dynamics (YLCD) methodology to analyse the behaviour of the vegetation, which consists of a combined multitemporal study of the NDVI and LST parameters on a yearly basis. Throughout the 1981-2001 period, trend analysis of the YLCD parameters emphasizes the areas that have endured the greatest changes in their vegetation. This result is corroborated by results from previous studies.
\end{abstract}

\section{Introduction}

The vegetation of the Iberian Peninsula has suffered changes in past decades, which have been evidenced in previous studies (FAO 2000, 2005, Vicente-Serrano and Heredia-Laclaustra 2004, UNEP 2005, Julien et al. 2006). These changes can be summarized in desertification in the south of the peninsula (Julien et al. 2006), while forests in the north have seen their extension increase (FAO 2000, 2005, Vicente-Serrano and Heredia-Laclaustra 2004). These changes have been related to the influence of the North Atlantic Oscillation for the south of the peninsula (Vicente-Serrano and Heredia-Laclaustra 2004).

The vegetation of the Iberian Peninsula, in particular, and more generally at a global scale, has been studied using vegetation indices only (Lobo et al. 2004, Vicente-Serrano and Heredia-Laclaustra 2004); in most cases, through the use of the normalized difference vegetation index (NDVI) (Rouse et al. 1973). However, this index suffers from flaws, among which is its saturation of over-dense vegetation covers (Asner et al. 2000). Therefore, this parameter has to be combined with other parameters to increase its relevance. The Advanced Very High Resolution Radiometer (AVHRR) sensor, onboard the National Oceanic and Atmospheric Administration (NOAA) satellite

*Corresponding author. Email: yves.julien@uv.es 
series, has provided NDVI data for historical records. This sensor also provides data that allow the estimation of land surface temperature (LST) using, for example, the splitwindow method developed by Sobrino and Raissouni (2000). However, this parameter is temporally unstable, due to the orbital drift that contaminates NOAA-AVHRR data (McGregor and Gorman 1994).

This study aims at using the data acquired by the NOAA-AVHRR sensor for the multitemporal study of the vegetation in the Iberian Peninsula from two biophysical parameters, namely NDVI and LST. Both parameters are monitored on a yearly basis to distinguish between vegetation types over the Iberian Peninsula, by using the yearly land-cover dynamics (YLCD) method (Julien and Sobrino 2009). The results obtained by this method allow the temporal analysis of the changes suffered by the vegetation of the Iberian Peninsula in past decades.

\section{Data}

The pathfinder AVHRR land (PAL) (Smith et al. 1997) database provides data at a global scale, with a spatial resolution of $0.1^{\circ} \times 0.1^{\circ}$ and a temporal resolution of 10 days, from July 1981 to September 2001. Despite the coarse spatial resolution of PAL data, which presents the inconvenience of averaging the retrieved data over various vegetation species, conclusions at the biome scale can still be drawn. For each 10-day period, five images are available, which correspond to visible (channel 1), near-infrared (channel 2) and thermal infrared (channels 4 and 5) wavelengths, as well as NDVI data. Visible and near-infrared data are provided as atmospherically corrected reflectances, while thermal infrared data are provided as top of atmosphere brightness temperatures. These images are provided in the standard latitude/longitude projection (also called plate carrée) and are composited using the maximum value compositing (MVC) method, which consists of identifying, for each pixel and within each 10-day period, the day for which the retrieved NDVI is maximum. This way, the quality of the NDVI information is retained. Moreover, the MVC technique favours acquisitions with a restricted range of view zenith angles and acquisitions viewing in the forward direction, therefore selecting the pixels nearest to nadir. The maximum value is also assumed to correspond to a minimum in aerosol and water vapour contents and cloud cover (Holben 1986, James and Kalluri 1994). Atmospheric effects were corrected using the method developed by Gordon et al. (1988), which includes a correction for ozone absorption (McPeters et al. 1993). As a consequence, 36 images per year are available for each channel during the 20 years covered by the PAL dataset.

A subset corresponding to the Iberian Peninsula has been extracted for the whole PAL dataset. Figure 1 shows the global land-cover classification corresponding to the study area (GLC 2003).

\section{Methodology}

A flow chart of the whole methodology is shown in figure 2. This methodology can be divided into two parts: LST estimation and application of the YLCD method.

\subsection{LST estimation}

The method developed by Sobrino and Raissouni (2000) has been used in order to calculate LST. Emissivities are estimated first from NDVI values, and then total atmospheric water vapour content is computed. 


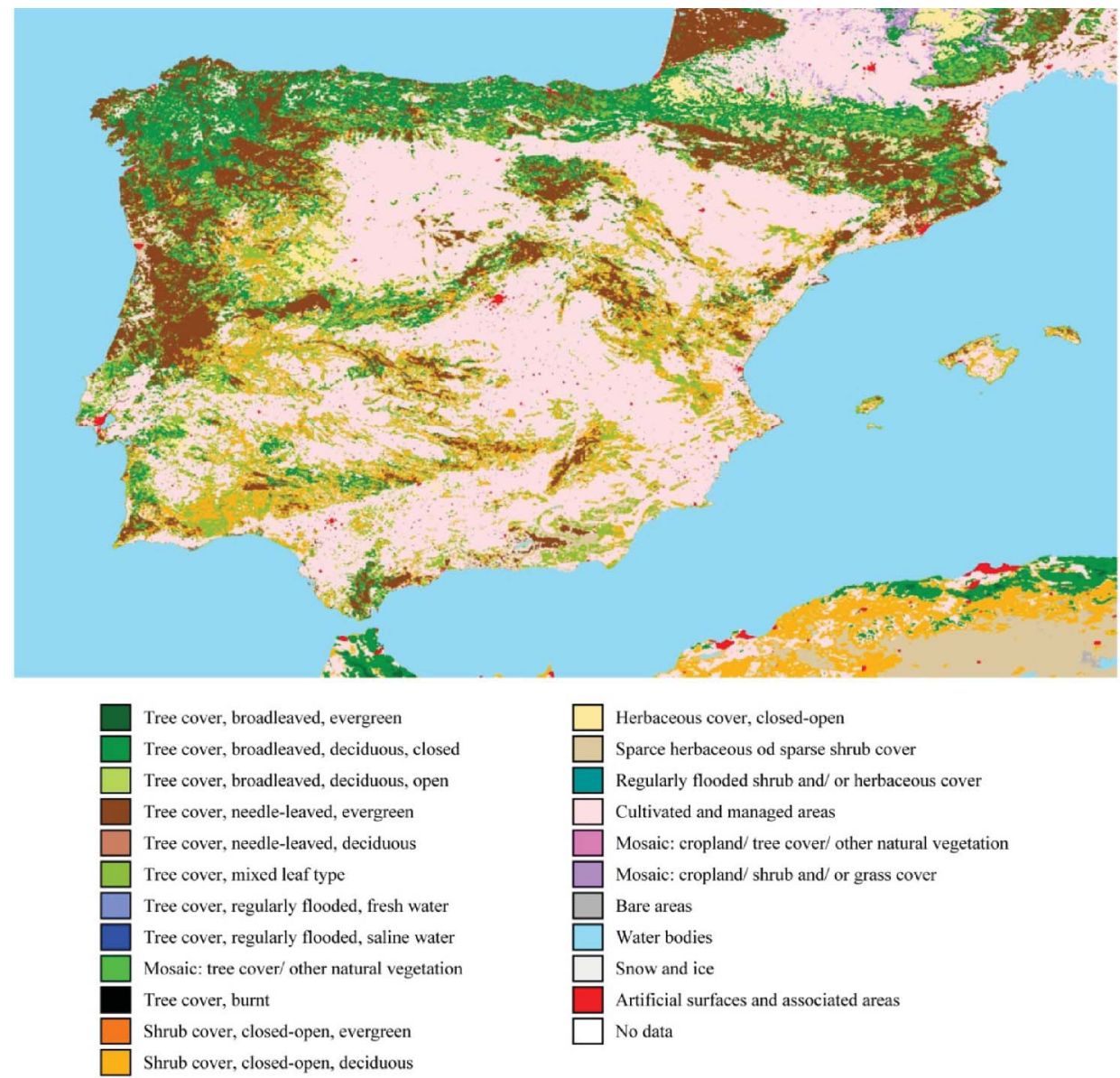

Figure 1. Land-cover classification for the Iberian Peninsula (adapted from Global Land Cover (GLC) 2000 database, European Commission, Joint Research Centre, 2003, http:// bioval.jrc.ec.europa.eu/products/glc2000/glc2000.php

The image has been divided into three zones, according to their NDVI values. The mean emissivity $\varepsilon$ (average of the emissivities for channels 4 and 5 of the AVHRR sensor) and the spectral variation of emissivity $\Delta \varepsilon$ (emissivity difference between both channels) are estimated as follows (all equations are taken from Sobrino and Raissouni (2000)):

- NDVI $<0.2$. In this case, the surface is assumed to be bare soil, where the emissivity is calculated from the channel 1 surface reflectance $\left(R_{1}\right)$ :

$$
\varepsilon=0.980-0.042 R_{1}
$$

and

$$
\Delta \varepsilon=-0.003-0.029 R_{1} .
$$

- $0.2<\mathrm{NDVI}<0.5$. The surface is then assumed to be a mix of bare soil and vegetation, so the emissivity can be estimated from the proportion of vegetation $P$ (unitless): 


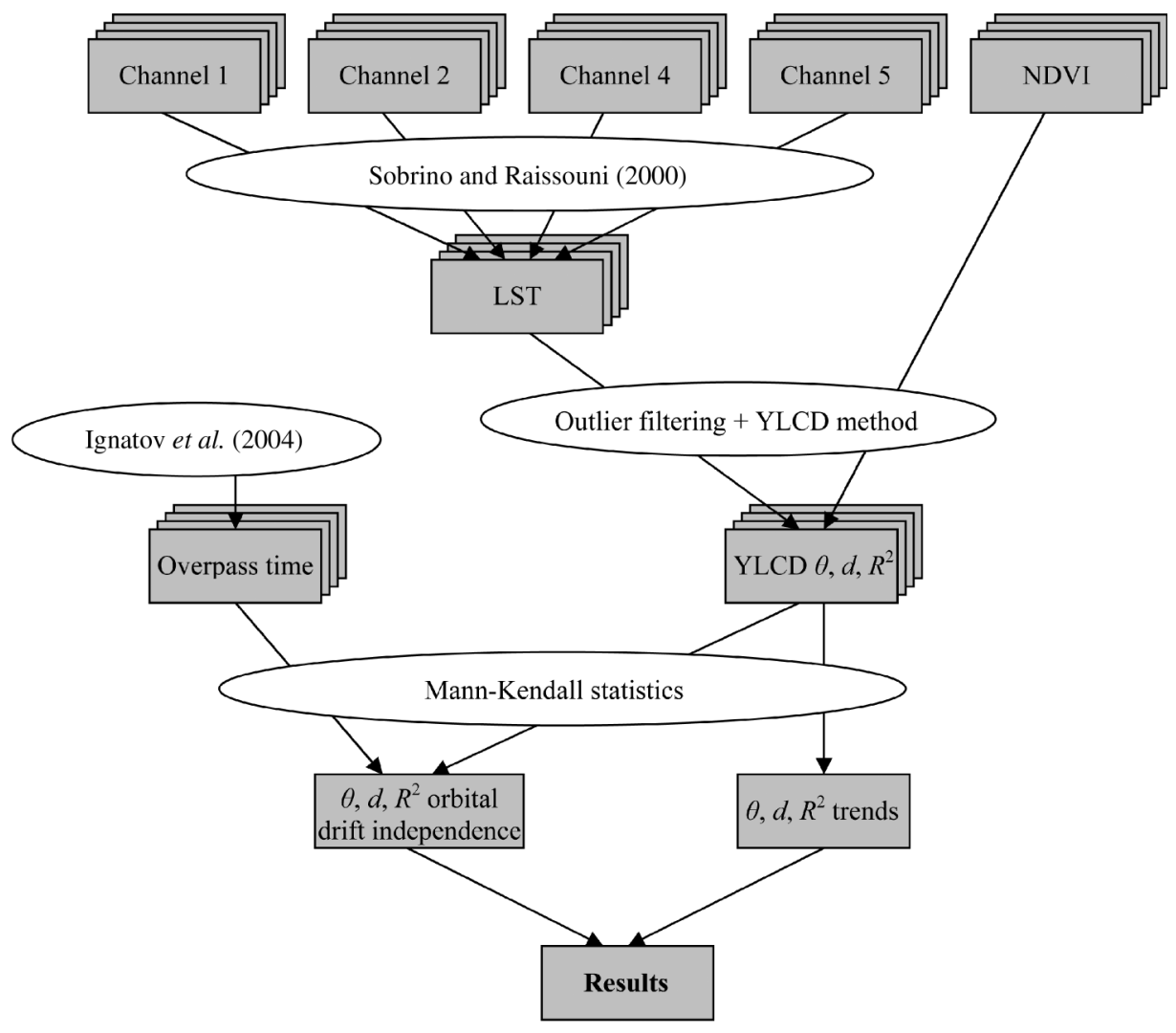

Figure 2. Flow chart of the proposed methodology.

$$
\varepsilon=0.971-0.018 P
$$

and

$$
\Delta \varepsilon=0.006(1-P),
$$

where $P$ is calculated from the NDVI itself (Carlson and Ripley 1997):

$$
P=\frac{((\mathrm{NDVI})-0.2)^{2}}{0.09} .
$$

- NDVI $>0.5$. The surface is assumed to be vegetation only, so the emissivity can be estimated as:

$$
\varepsilon=0.985
$$

and

$$
\Delta \varepsilon=0
$$

This method allows emissivity estimation with an error of 0.01 (Sobrino et al. 1999). For more details on the advantages and disadvantages of estimating emissivities from NDVI data, see Jimenez-Muñoz et al. (2006) and Sobrino et al. (2008). 
The total atmospheric water vapour is estimated by using the variance-covariance ratio $\left(R_{54}\right)$, which is calculated from a neighbourhood of $N$ pixels of channels 4 and 5 images:

$$
R_{54}=\frac{\sum_{k=1}^{N}\left(T_{4 k}-T_{4 \mathrm{o}}\right)\left(T_{5 k}-T_{5 \mathrm{o}}\right)}{\sum_{k=1}^{N}\left(T_{4 k}-T_{4 \mathrm{o}}\right)^{2}},
$$

where $T_{4 k}$ and $T_{5 k}$ are the radiometric temperatures (in $\mathrm{K}$ ) for the $k$ th pixel of the neighbourhood in channels 4 and 5 images, respectively, and $T_{40}$ and $T_{5 \mathrm{o}}$ are the average values for the neighbourhood in channels 4 and 5 images, respectively. From this ratio, the total atmospheric water vapour $\left(W\right.$, in $\left.\mathrm{g} \mathrm{cm}^{-2}\right)$ is estimated according to:

$$
W=0.26-14.253 \cos (\theta) \ln R_{54}-11.649\left(\cos (\theta) \ln R_{54}\right)^{2},
$$

where $\theta$ is (in this equation (9) only) the viewing angle for the corresponding pixel (in ${ }^{\circ}$ ). This method gives an estimation of total atmospheric water vapour with an error of $0.5 \mathrm{~g} \mathrm{~cm}^{-2}$ (Sobrino et al. 1999).

From the values estimated above (average emissivity, spectral variation of emissivity and water vapour), LST is obtained by using the following formula:

$$
\begin{aligned}
\mathrm{LST}= & T_{4}+1.40\left(T_{4}-T_{5}\right)+0.32\left(T_{4}-T_{5}\right)^{2}+0.83+(57-5 W)(1-\varepsilon) \\
& -(161-30 W) \Delta \varepsilon,
\end{aligned}
$$

where $T_{4}$ and $T_{5}$ correspond to AVHRR brightness temperatures in thermal channels 4 and 5. This parameter is estimated with an error of $1.3 \mathrm{~K}$ (Sobrino and Raissouni 2000).

Once the LST and NDVI parameters for the whole dataset are obtained, yearly time series are screened out for outliers by computing a histogram of value occurrences for both parameters and removing isolated values at both ends of the histogram.

\subsection{YLCD method}

The YLCD method simultaneously analyses the behaviour of the NDVI and LST parameters for a given pixel. This method allows extracting, on an annual basis, three parameters that describe the type and seasonality of the vegetation present in the considered pixel. This way, the size of the data to be analysed for change detection is reduced, since year-long observations for two parameters (NDVI and LST) are summarized in the three parameters per year. A thorough description of the method can be found in Julien and Sobrino (2009).

To this end, normalized LST (LŜT, unitless) is plotted against NDVI for each pixel. Normalized LST is defined as:

$$
(\mathrm{LST})=\frac{\left(\left(\mathrm{LST}-\left(\mathrm{LST}_{\min }\right)\right)\right.}{\left(\left(\mathrm{LST}_{\max }\right)-\left(\mathrm{LST}_{\min }\right)\right)},
$$

where $\mathrm{LST}_{\min }$ and $\mathrm{LST}_{\max }$ correspond to 240 and $340 \mathrm{~K}$ respectively, which allows orthonormalizing the NDVI-LST space. $\mathrm{LST}_{\max }$ also corresponds to the upper limit of the thermal range of AVHRR, and $\mathrm{LST}_{\text {min }}$ has been chosen in order to normalize inaccuracies in NDVI and LST parameters to $1-2 \%$ of their respective range. 
Moreover, this normalization has the advantage of setting $\theta$ (see below) to the whole $-90^{\circ}$ and $90^{\circ}$ range (see Julien and Sobrino (2009)).

Graphic representation of the 36 LST values against the corresponding 36 NDVI values for a given year allows calculating the regression line between both parameters for each pixel, from which the following three parameters are derived.

$\theta$ (varying between $-90^{\circ}$ and $+90^{\circ}$ ) is defined as the angle between the axis of abscissas and the regression line, and is related to the considered vegetation type. As an example, arid areas tend to have extreme $\theta$ values (close to $+90^{\circ}$ or $-90^{\circ}$ ), corresponding to an important thermal yearly amplitude with regards to almost unchanging NDVI values. Semi-arid areas usually have negative values of $\theta$ since their vegetation is more photosynthetically active when the temperature is lower. Tropical rainforests correspond to $\theta$ values around zero $\left( \pm 10^{\circ}\right)$, with fluctuating NDVI values depending on the season, while canopy temperature (which is the LST retrieved from satellite) does not vary due to the ability of trees to regulate their temperature through evapotranspiration. Finally, temperate and polar areas have positive $\theta$ values, since NDVI maxima are reached during the summer when temperatures are higher.

$d$ (varying between 0 and 1 ) is defined as the length of the circannual dispersion for the considered pixel, projected on the regression line, and characterizes the seasonality of vegetation for this pixel. Mountain areas, where snow contribution to the pixel is preponderant in winter, tend to show high values of $d$, while arid and semi-arid areas present low $d$ values, due to a lower circannual variation of the NDVI.

$R^{2}$ (varying between 0 and 1 ) is obtained from the aforementioned regression line and characterizes the goodness-of-fit between the circannual behaviour of the pixel and our linear model. Arid areas, where the noise in the measurements is higher, present lower values of $R^{2}$.

This YLCD method has thus been applied to the whole PAL Iberian Peninsula dataset. As a result, time series of $\theta, d$ and $R^{2}$ consist of 21 annual values covering the 1981-2001 period.

\section{Results}

Figure 3(a) shows the spatial distribution of the retrieved YLCD parameters for the Iberian Peninsula, coded as an Intensity Hue Saturation (IHS) image, where intensity

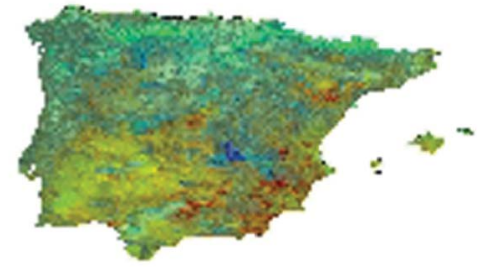

(a)

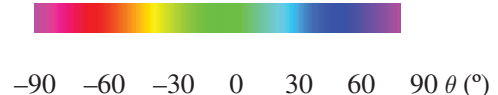

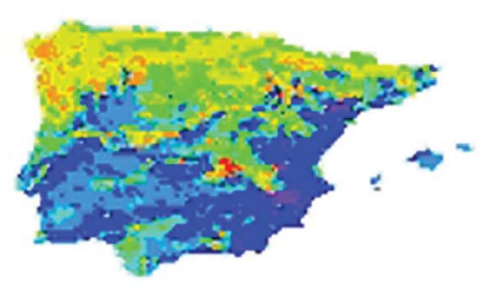

(b)

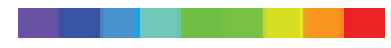

$-90-70-50-30-101030507090 \theta\left(^{\circ}\right)$

Figure 3. Retrieved parameters from the YLCD method for the Iberian Peninsula as (a) IHS composite image of YLCD parameters (intensity: $d$; hue: $\theta$; saturation: $R^{2}$ ) and $(b)$ for $\theta$ only. Vegetation types appear clearly differentiated by the YLCD parameters. 
corresponds to $d$, hue to $\theta$ and saturation to $R^{2}$ (Julien and Sobrino 2009). This figure shows a clear differentiation of the vegetation types, with arid areas appearing in red, semi-arid areas in yellow, while forests and vegetated areas appear in different shades of blue. Mountain areas display a different shade of blue because of their higher variation in NDVI and LST circannual amplitude due to snow presence in winter (Pyreneans), translated in colour intensity through $d$. This is evidenced in figure $3(b)$, where only $\theta$ is described, showing the distribution of vegetation types in the Iberian Peninsula.

The retrieved parameter time series (1981-2001) were tested for trends using the Mann-Kendall trend tests (Kendall 1975, Libizeller and Grimvall 2002) at the 90\% confidence level, and trends were retrieved using ordinary least squares regression for the pixels passing the Mann-Kendall trend tests. Extreme trends were defined as the trends outside of plus/minus one standard deviation around the average significant trend for the peninsula. These extreme trends are shown in figure 4 as a function of the $\theta$ value of the corresponding pixel (figure 3(b)) for all parameters. Significant decreasing trends in $\theta$ values are located mainly in the northwest of the peninsula, at the northern boundary between Spain and Portugal, while significant increasing trends for this same parameter show a more fragmented pattern. As for $d$, a large area of Castilla-laMancha shows a clear significant decreasing trend, while significant increasing trends are more dispersed geographically over western and southern Spain. Finally, significant decreasing trends in $R^{2}$ are located mainly in the southwest quarter of Spain, while significant increasing trends are dispersed in the whole peninsula.

Before explaining the trends retrieved by application of the YLCD method, one has to assess the independence of the retrieved parameters from the orbital drift (McGregor and Gorman 1994), which contaminates the NDVI and LST values retrieved from the PAL database. Therefore, independence tests have been carried out between, on the one hand, $\theta, d$ and $R^{2}$, and on the other hand, averaged overpass time series, obtained by computing yearly averages from overpass times series estimated using the method developed by Ignatov et al. (2004). These independence tests are based on Kendall rank correlation (Hipel and McLeod 1994), and since overpass times are directly related to NOAA orbital drift, these tests assess the independence of the YLCD parameters from NOAA orbital drift. Figure 5 shows the confidence levels reached for each parameter obtained by the YLCD method for these independence tests. As figure 5( $a$ ) shows, $\theta$ has good independence from the orbital drift $(p>0.80)$, except for areas in central Portugal, Cantabria and in the Valencia region. For $d$, lower independence $(p<0.80)$ from orbital drift corresponds to the northernmost fringe of Spain, from A Coruña to Barcelona. Finally, $R^{2}$ is independent from the orbital drift (probability level $p>0.80$ ) for the whole Iberian Peninsula, except for the Balearian Islands and coastal central Portugal. Therefore, extreme trends for all these areas have to be analysed with the influence of the orbital drift in mind.

\section{Discussion}

Trends in $\theta$ correspond to changes in land occupation, and the significant decreasing trend observed at the northern border between Spain and Portugal corresponds to a lesser yearly temperature cycle $\left(\theta\right.$ decreasing from values around $\left.40^{\circ}\right)$, which is concordant with the reports of the Food and Agriculture Organization (FAO 2000, 2005), which describe successive increases in forest cover over Spain, especially in the northern and western regions (Basque Country, Cantabria, Asturias, Galicia) and 
northern Portugal. Increases in forest cover for Spain reached $860 \mathrm{~km}^{2}$ per year $(0.6 \%$ of total forest area) between 1990 and 2000 and $2960 \mathrm{~km}^{2}$ per year between 2000 and 2005 (FAO 2000, 2005). For the same periods, Portugal saw its forest cover increased

Decreasing trends

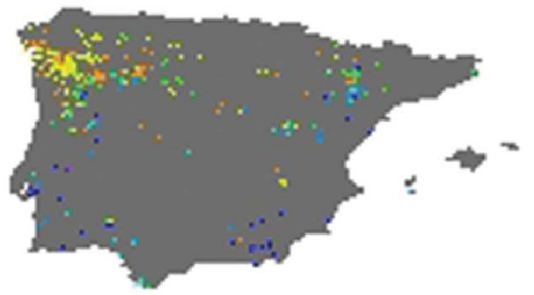

(a)

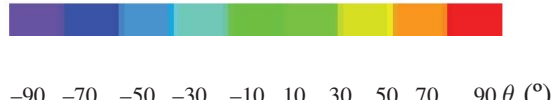

$\begin{array}{llllllllll}-90 & -70 & -50 & -30 & -10 & 10 & 30 & 50 & 70 & 90 \theta\end{array}\left(^{\circ}\right)$

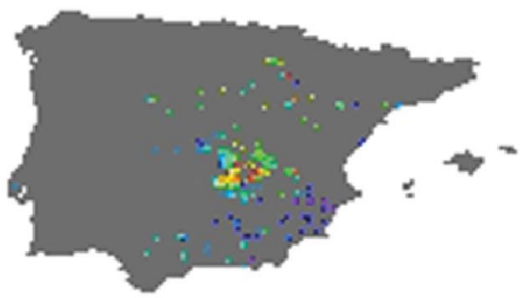

(b)

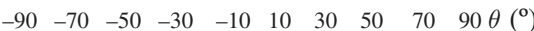

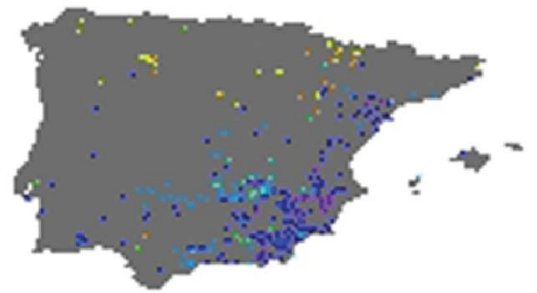

(c)

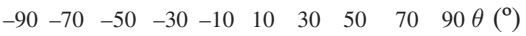

Increasing trends

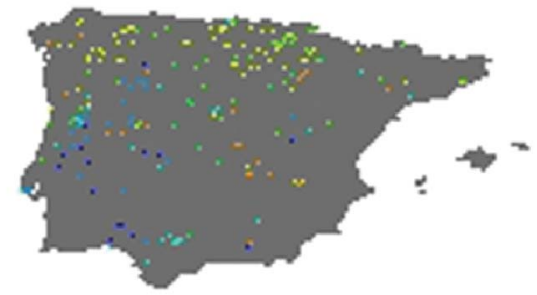

(d)
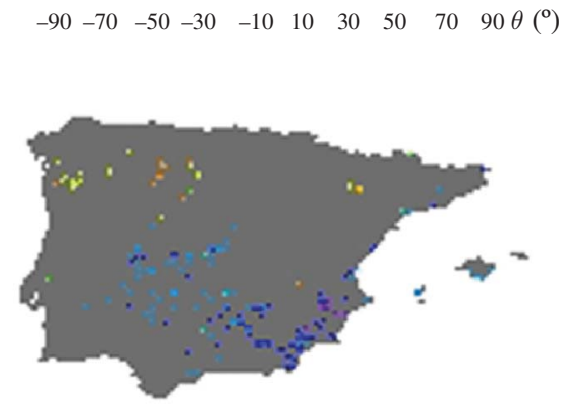

(e)

$\begin{array}{llllllllll}-90 & -70 & -50 & -30 & -10 & 10 & 30 & 50 & 70 & 90\end{array} \quad\left(^{\circ}\right)$

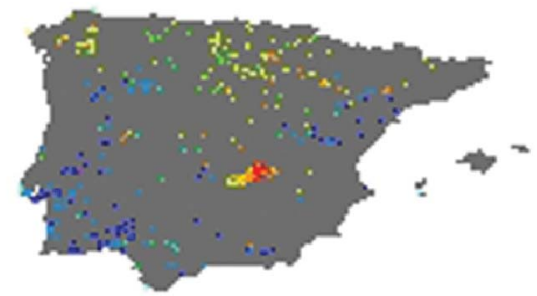

$(f)$

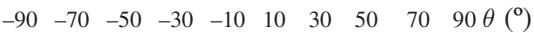

Figure 4. Extreme trends (identified as superior to one standard deviation) for each YLCD parameter, and displayed as a function of $\theta:(a, d) \theta,(b, e) d$ and $(c, f) R^{2}$. Coloured pixels correspond to vegetation types for which there is a significant decrease (left) or increase (right) in the corresponding YLCD parameter. 


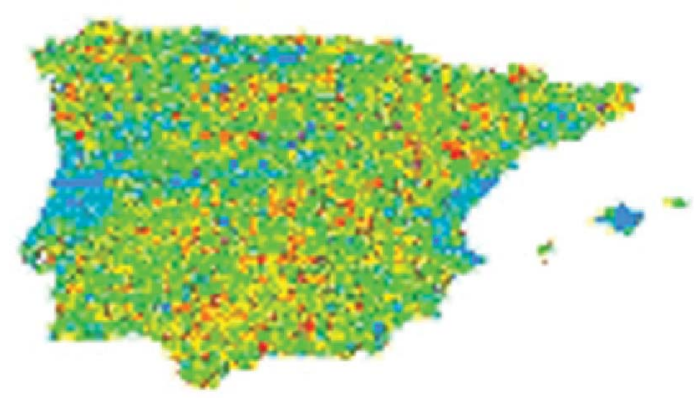

(a)
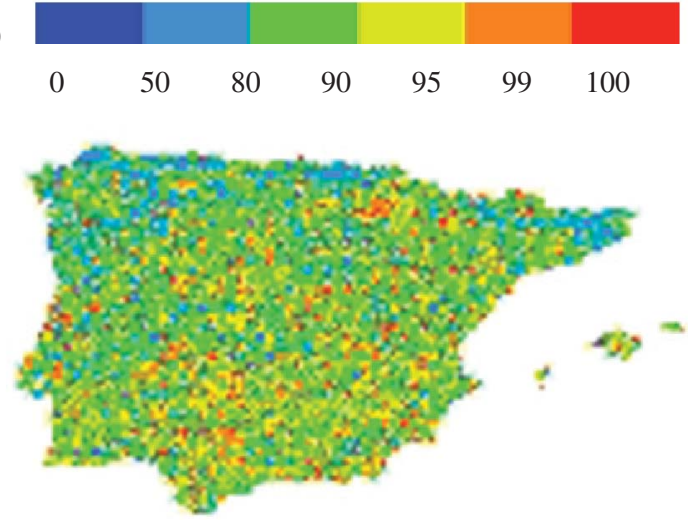

(b)
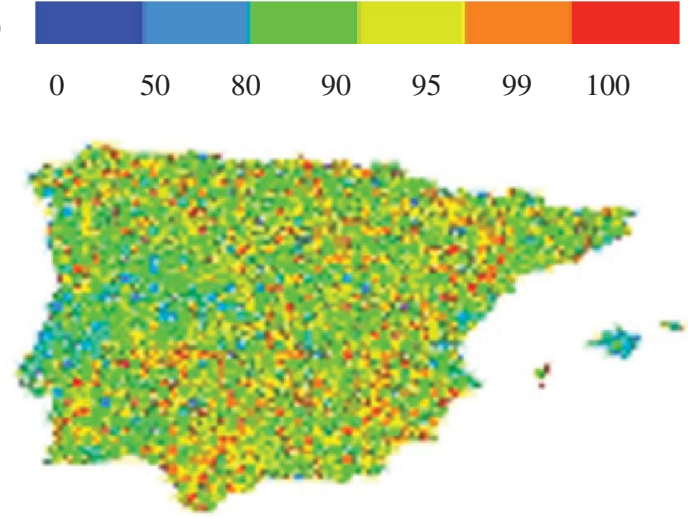

(c)

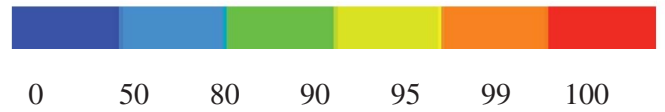

Figure 5. Confidence level for independence tests between yearly satellite average overpass time (illustrating satellite orbital drift) and $(a) \theta,(b) d$ and $(c) R^{2}$ YLCD parameters. The whole Iberian Peninsula shows an independence of YLCD parameters from NOAA orbital drift at the $50 \%$ confidence level, with most of the peninsula showing independence at the $80 \%$ confidence level. 
by $570 \mathrm{~km}^{2}$ (1.7\% of total forest area) and $400 \mathrm{~km}^{2}$ respectively (FAO 2000, 2005). Significant decreasing trends in $d$ correspond to a decrease of seasonality. Such trends can be found mainly in central Spain, in areas defined in the Global Land Cover 2000 classification as 'cultivated and managed areas' (figure 1). This area has been identified as undergoing desertification in Julien et al. (2006). This area has also been singled out as showing a decreasing trend in yearly integrated NDVI between 1982 and 2000 (Vicente-Serrano and Heredia-Laclaustra 2004). Since yearly integrated NDVI is a proxy for vegetation production (Field et al. 1995, Prince and Goward 1995), this validates our observations. Moreover, this same area appears with significant increasing trends in $R^{2}$ (figure $4(f)$ ), which confirms the previously observed desertification trend for this area, since high $R^{2}$ values generally correspond to arid areas (Julien and Sobrino 2009). The other significant trends in $d$ are difficult to interpret due to their spatially dispersed character. However, increasing trends in southern Spain are probably due to irrigation implementation in response to the documented desertification of the area (Julien et al. 2006). Significant trends in $R^{2}$ also show an irregular pattern, except for the afore-mentioned central area, although decreasing trends in $R^{2}$ are mainly located in the southeastern part of Spain, in areas labelled as 'cultivated and managed areas', where additional information on agricultural practice changes would be needed for a thorough analysis.

\section{Conclusion}

This study has used the LST and NDVI to retrieve vegetation changes in the Iberian Peninsula, through the analysis of the circannual trajectories of both parameters. This analysis has been carried out using the YLCD method, which shows to be generally independent of the orbital drift that contaminates the data. This method allows the identification of the areas suffering significant changes in parameters related to vegetation type and seasonality, as well as confidence in the model. Most of the areas showing significant changes in at least one of these parameters have been documented in previous studies as suffering desertification or forest extension, validating the approach.

\section{Acknowledgements}

The authors wish to thank the TERMASAT project (Ministerio de Educación y Ciencia, project ESP2005-07724-C05-04) for their financial support.

\section{References}

Asner, G.P., Townsend, A.R. and Braswell, B.H., 2000, Satellite observation of El Niño effects on Amazon forest phenology and productivity. Geophysical Research Letters, 27, pp. 981-984.

CARlson, T. and Ripley, D., 1997, On the relation between NDVI, fractional vegetation cover, and leaf area index. Remote Sensing of Environment, 62, pp. 241-252.

Food and Agriculture Organization (FAO), 2000, Global forest resources assessment 2000. Available online at: ftp://ftp.fao.org/docrep/fao/003/Y1997E/FRA 2000 Main report.pdf.

Food and Agriculture Organization (FAO), 2005, Global forest resources assessment 2005. Available online at: ftp://ftp.fao.org/docrep/fao/008/A0400E/A0400E00.pdf.

Field, C.B., Randerson, J.T. and Malmström, C.M., 1995, Global net primary production: combining ecology and remote sensing. Remote Sensing of Environment, 51, pp. 74-88. 
Global Land Cover (GLC), 2003, Global Land Cover 2000 database. European Commission, Joint Research Center 2003. Available online at: http://bioval.jrc.ec.europa.eu/products/ glc2000/glc2000.php.

Gordon, H.R., Brown, J.W. and Evans, R.H., 1998, Exact Rayleigh scattering calculations for use with the Nimbus-7 coastal zone colour scanner. Applied Optics, 27, pp. 2111-2122.

Hipel, K.W. and McLeod, A.I., 1994, Time Series Modelling of Water Resources and Environmental Systems (Amsterdam, The Netherlands: Elsevier Scientific Publishing Company).

Holben, B.N., 1986, Characteristics of maximum values composite images from temporal AVHRR data. International Journal of Remote Sensing, 7, pp. 1417-1434.

Ignatov, A., Laszlo, I., Harrod, E.D., Kidwell, K.B. and Goodrum, G.P., 2004, Equator crossing times for NOAA, ERS and EOS sun-synchronous satellites. International Journal of Remote Sensing, 25, pp. 5255-5266.

JAmes, M.E. and Kalluri, S.N.V., 1994, The AVHRR land data set: an improved coarse resolution data set for terrestrial monitoring. International Journal of Remote Sensing, 15, pp. 3347-3363.

Jiménez-Muñoz, J.C., Sobrino, J.A., Gillespie, A., Sabol, D. and Gustafson, W.T., 2006, Improved land surface emissivities over agricultural areas using ASTER NDVI. Remote Sensing of Environment, 103, pp. 474- 487.

Julien, Y. and Sobrino, J.A., 2009, The yearly land cover dynamics (YLCD) method: an analysis of global vegetation from NDVI and LST parameters. Remote Sensing of Environment, 113, pp. 329-334.

Julien, Y., Sobrino, J.A. and Verhoef, W., 2006, Changes in land surface temperatures and NDVI values over Europe between 1982 and 1999. Remote Sensing of Environment, 103, pp. $43-55$.

Kendall, M.G., 1975, Rank Correlation Methods (London, UK: Charles Griffin).

Libizeller, C. and Grimvall, A., 2002, Performance of partial Mann-Kendall test for trend detection in the presence of covariates. Environmetrics, 13, pp. 71-84.

Lobo, A., Legendre, P., Rebollar, J.L.G., Carreras, J. and Ninot, J.-M., 2004, Land cover classification at a regional scale in Iberia: separability in a multi-temporal and multi-spectral data set of satellite images. International Journal of Remote Sensing, 25, pp. 205-213.

McGregor, J. and Gorman, A.J., 1994, Some consideration for using AVHRR data in climatological studies. 1. Orbital characteristics of NOAA satellites. International Journal of Remote Sensing, 15, pp. 537-548.

McPeters, R.D. Krueger, A.J., Bhartia, P.K., Herman, J.R., Oaks, A., Ahmad, Z., Cebula, R.P., Schlesinger, B.M., Swissler, T., Taylor, S.L., Torres, O. and Wellemeyer, C.G., 1993, Nimbus-7 Total Ozone Mapping Spectrometer (TOMS) data products user's guide. NASA Reference Publication 1323.

Prince, S.D. and GowARD, S.N., 1995, Global primary production: a remote sensing approach. Journal of Biogeography, 22, pp. 815-835.

Rouse, J.W., Haas, R.H., Schell, J.A. and Deering, D.W., 1973, Monitoring vegetation systems in the Great Plains with ERTS. In 3rd ERTS Symposium, NASA SP-351 I, pp. 309-317.

Smith, P.M., Kalluri, S.N. V., Prince, S.D. and Defries, R., 1997, The NOAA/NASA pathfinder AVHRR $8 \mathrm{~km}$ land data set. Photogrammetric Engineering and Remote Sensing, 63, pp. 12-31.

Sobrino, J.A. and RAissouni, N., 2000, Toward remote sensing methods for land cover dynamic monitoring: application to Morocco. International Journal of Remote Sensing, 21, pp. 353-366.

Sobrino, J.A., Raissouni, N., Simarro, J., Nerry, F. and Petitcolin, F., 1999, Atmospheric water vapour content over land surfaces derived from the AVHRR data: application to 
the Iberian Peninsula. IEEE Transactions on Geoscience and Remote Sensing, 37, pp. $1425-1434$.

Sobrino, J.A., Jiménez-Muñoz, J.C., Sòria, G., Romaguera, M., Guanter, L., Moreno, J., Plaza, A. and Martínez, P., 2008, Land surface emissivity retrieval from different VNIR and TIR sensors. IEEE Transactions on Geoscience and Remote Sensing, 46, pp. 316-327.

United Nations Environment Programme (UNEP), 2005, One planet many people: atlas of our changing environment. Division of Early Warning and Assessment (DEWA), United Nations Environment Programme (UNEP), Nairobi, Kenya. Available online at: http://na.unep.net/OnePlanetManyPeople/index.php.

Vicente-Serrano, S.M. and Heredia-Laclaustra, A., 2004, NAO influence on NDVI trends in the Iberian Peninsula (1982-2000). International Journal of Remote Sensing, 25, pp. 2871-2879. 